\title{
Progesterone and oestrogen concentrations in plasma of Barbary sheep (aoudad, Ammotragus lervia) compared with those of domestic sheep and goats during pregnancy
}

\author{
M. H. Hamon and R. B. Heap \\ AFRC Institute of Animal Physiology and Genetics Research, Babraham, Cambridge CB2 4AT, UK
}

\begin{abstract}
Summary. Steroid hormone concentrations have been measured in the peripheral plasma of 3 Barbary sheep over 3 breeding seasons. During pregnancy mean progesterone values rose initially and after a small decline between Days 30 and 50, increased again and remained between 17 and $28 \mathrm{nmol} / 1$ until the last 2 days of pregnancy. Oestradiol- $17 \beta$ reached a peak of about $300 \mathrm{pmol} / 1$ during mid-pregnancy, increasing to over $400 \mathrm{pmol} / \mathrm{l}$ in the last 5 days of pregnancy. Oestrone sulphate began to increase in concentration from about Day 40 of pregnancy and reached a peak of about $19 \mathrm{nmol} / \mathrm{l}$ by Day 120 . Following a slight decrease from Day 130, there was a further rise in values just before parturition. Values for these steroids in the Barbary sheep studied were between those expected for domestic sheep and goats.
\end{abstract}

Keyw'ords: progesterone; oestrogen; pregnancy; Barbary sheep

\section{Introduction}

The Barbary sheep is one of several species in which the diploid chromosome number is intermediate $(2 n=58)$ between those of the sheep $(2 n=54)$ and goat $(2 n=60)$. In sheep the corpora lutea can be dispensed with after mid-pregnancy since the placenta secretes large amounts of progesterone (Casida \& Warwick, 1945; Denamur \& Martinet, 1955), unlike the goat (DrummondRobinson \& Asdell, 1926; Linzell \& Heap, 1968; Sheldrick et al., 1980b). Flint et al. (1983) reported that Barbary sheep resembled the domestic sheep rather than the goat from the point of view of the source of progesterone required for the maintenance of pregnancy.

The purpose of the present investigation was to determine whether the similarity observed between the Barbary sheep and domestic sheep in respect of the endocrinological maintenance of pregnancy also pertains to placental oestrogen production. In the sheep the circulating concentration of total unconjugated oestrogens remains low during pregnancy until shortly before parturition when a sharp increase occurs (Challis, 1971), whereas in the goat it increases progressively throughout (Challis \& Linzell, 1971).

\section{Materials and Methods}

Animals. Three female Barbary sheep, 3-5 years old at the start of the study, were fed hay ad libitum and $0.5 \mathrm{~kg}$ dairy concentrates/day, allowed free access to water and kept under natural temperature and daylight conditions. A fertile Barbary ram was housed with the females during the breeding season, beginning in November and ending between February and April. Detection of mating was achieved by the use of a raddled ram.

Samples. Blood samples during 3 consecutive breeding seasons were taken by jugular venepuncture and transferred into heparinized syringes. Samples were obtained at weekly intervals during early pregnancy, increasing to thrice weekly during the last month of pregnancy and daily during the week before parturition was expected. Packed red cell volume was determined by microhaematocrit centrifugation and the remaining sample was centrifuged in a 
microcentrifuge (Beckman U.K., High Wycombe, Bucks, UK) at $4^{\circ} \mathrm{C}$ for $5 \mathrm{~min}$ at $12400 \mathrm{~g}$. Plasma was removed and stored in aliquants at $-20^{\circ} \mathrm{C}$ until required for steroid analysis.

Radioimmunoassays. Progesterone, oestradiol- $17 \beta$ and oestrone sulphate were determined by previously described methods validated for plasma from Barbary sheep (Heap \& Hamon, 1979; Ricketts et al., 1980). Progesterone was measured using a polyclonal antiserum (18/3) raised in a sheep against 11 $\alpha$-hemisuccinyl-BSA at a dilution of 1:5000 and the specificity of this antiserum has been reported by Sheldrick et al. (1980a). Assay sensitivity was $19.7 \pm 3.4 \mathrm{fmol} /$ tube with inter- and intra-assay coefficients of variation $7.8 \%$ and $17.9 \%$, respectively. Oestradiol$17 \beta$ was measured using a polyclonal antiserum (BF510/5, kindly supplied by Dr B. J. A. Furr). Assay sensitivity was $14.7 \pm 5.1 \mathrm{fmol} /$ tube with inter- and intra-assay coefficients of variation $5.6 \%$ and $16.2 \%$, respectively. Antiserum E001 (Steranti, St Albans, Herts, UK) was used to measure oestrone released by enzyme hydrolysis of oestrone sulphate. Assay sensitivity was $28.2 \pm 4.9 \mathrm{fmol} /$ tube $(n=10)$, with inter-and intra-assay coefficients of variation 16.8 and $17.9 \%$, respectively.

\section{Results}

\section{Gestation length}

The length of gestation determined from 7 pregnancies over 3 years was $154.4 \pm 0 \cdot 7$ (mean \pm s.e.m.) days. The offspring were born during April with one exception of a birth in June and only one set of female twins was born during the study period.

\section{Plasma hormone concentrations}

Progesterone values rose initially to approximately $16 \mathrm{nmol} / \mathrm{l}$ between Days 10 and 20 of pregnancy, but then declined to about $9 \mathrm{nmol} / 1$ between Days 40 and 50 . From then until 1 day before parturition mean values remained between 17 and $28 \mathrm{nmol} / 1$ (Fig. la) before dropping to $<3 \mathrm{nmol} / \mathrm{l}$ on the day of delivery (Fig. $2 \mathrm{a}$ ).

Oestradiol concentrations varied from about 100 to $300 \mathrm{pmol} / 1$ between Days 40 and 150, but in the last 5 days mean values rose to over $400 \mathrm{pmol} / \mathrm{l}$ (Fig. 1b). There was more than a 2 -fold increase obtained in the available samples in oestradiol values during the $2448 \mathrm{~h}$ before the onset of delivery (Fig. 2b). Within a few hours after delivery, values had fallen to $<300 \mathrm{pmol} / \mathrm{l}$.

Oestrone sulphate concentrations began to rise from about Day 40 and reached a plateau of about $19 \mathrm{nmol} / 1$ by Day 120. This value was maintained until about 20 days pre partum when there was a slight decline in concentration (Fig. Ic), rising by 2 -fold about $24 \mathrm{~h}$ before parturition in the samples obtained (Fig. 2c). All steroids measured fell to low $(n=5)$ levels within 2 days after parturition, oestrone sulphate and oestradiol concentrations being below the detection limit of the assay and progesterone giving a mean value of $0.96 \pm 0.49 \mathrm{nmol} / 1$.

Haematocrit was monitored throughout each sampling period and gave mean values for each period of $47 \cdot 8 \pm 1 \cdot 8 \%(n=109), 44 \cdot 2 \pm 1 \cdot 5 \%(n=76)$ and $42 \cdot 1 \pm 1 \cdot 1 \%(n=8)$.

\section{Discussion}

The progesterone values reported in the present study are similar to those observed by Tsang (1978) in the sheep, although they failed to increase to the values found during the second half of pregnancy. This could be due to the fact that only one of the Barbary sheep studied carried twins, the other pregnancies being singletons, whereas all animals studied by Tsang (1978) carried either twins or triplets. Bassett et al. (1969) and Stabenfeldt et al. (1972) showed a lower progesterone concentration in sheep carrying a single fetus compared to those carrying twins and their values are also in good agreement with the data reported here. However, the pattern of change in progesterone concentration in Barbary sheep was much closer to that observed in the goat with a single fetus although the absolute values were somewhat higher than those in the goat (Thorburn \& Schneider, 1972). 

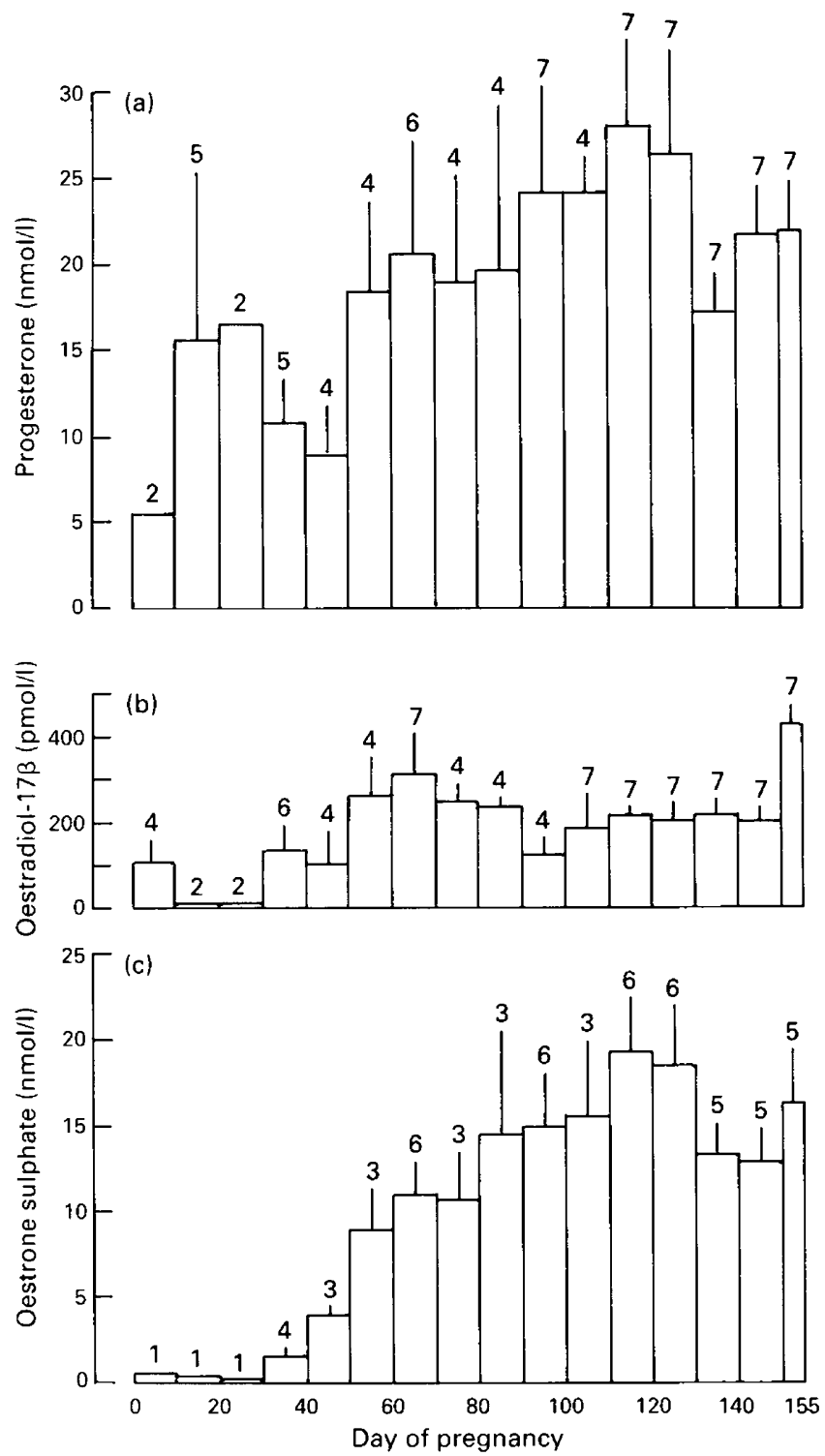

Fig. 1. Plasma concentration of (a) progesterone, (b) oestradiol-17 $\beta$, and (c) oestrone sulphate in Barbary sheep at different times of gestation. Values are means \pm s.e.m. for the number of samples indicated.

Flint et al. (1983) reported progesterone concentrations in jugular venous plasma of 4 individual Barbary females at approximately 14, 55, 125 and 140 days of pregnancy determined by blastocyst morphology, fetal weight and crown-rump length. The single values $(15 \cdot 3,9 \cdot 5,44 \cdot 5$ and $50.9 \mathrm{nmol} / 1$, respectively) fall within the range observed in the present study during early pregnancy but are higher than those found during late pregnancy. In the present study the progesterone concentration in peripheral plasma declined at about Day 50 and then recovered and this accords with the time when placental progesterone secretion becomes increasingly important in domestic sheep. Having in mind that uterine synthesis of progesterone occurs in the Barbary sheep during late pregnancy (Flint et al., 1983), there are clearly several similarities between this species and domestic sheep in terms of the source of progesterone secretion in pregnancy. 

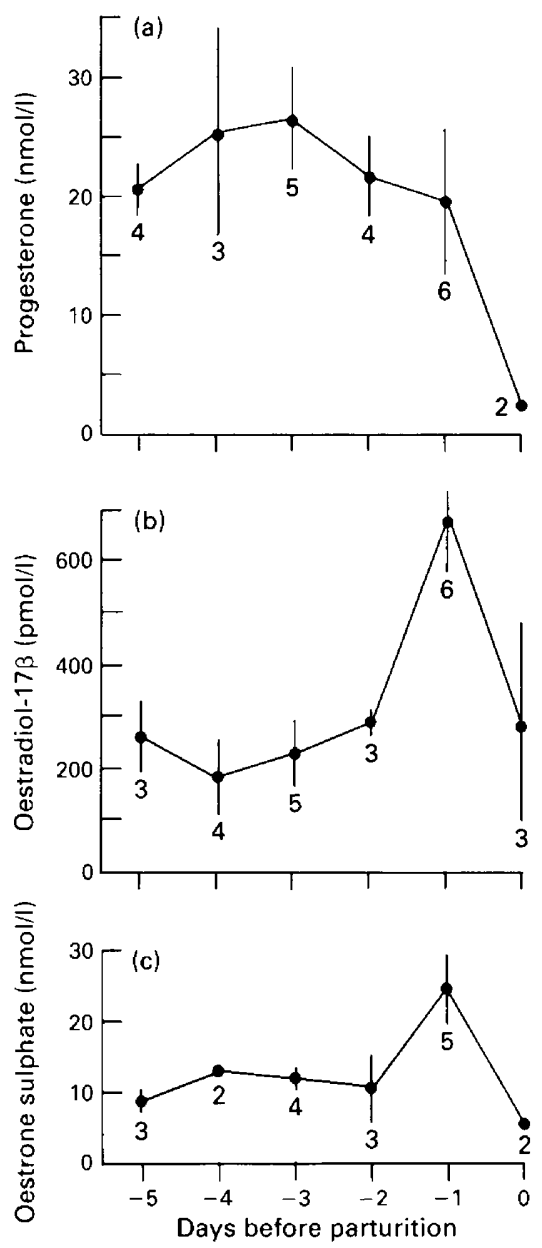

Fig. 2. Plasma concentrations of (a) progesterone, (b) oestradiol-17 $\beta$, and (c) oestrone sulphate in Barbary sheep during the last 5 days of gestation. Values are means \pm s.e.m. for the number of samples indicated.

Similarities between these species are also apparent from the pattern of oestrogen production. Oestradiol concentrations in peripheral plasma remained at a steady level for the majority of pregnancy $(100-300 \mathrm{pmol} / \mathrm{l})$. In the goat total unconjugated oestrogens increased progressively throughout pregnancy (Challis \& Linzell, 1971), whereas in the sheep they remained at low values for the majority of pregnancy (Challis, 1971). Oestrone sulphate was first detected in plasma of Barbary sheep after about Day 40, which agrees with observations of values in plasma for the sheep (Carnegie \& Robertson, 1978; Tsang, 1978) and in milk for sheep and goats (Heap et al., 1981). Oestrone sulphate, a major form of oestrogen during pregnancy, was present in goat plasma at values considerably greater (Heap et al., 1984) than those found in the Barbary sheep or domestic sheep (Tsang, 1978).

During the last 5 days of pregnancy, there was a decline in the progesterone concentration, this being most marked in the $24 \mathrm{~h}$ before parturition. Both oestradiol and oestrone sulphate showed a doubling in concentration $24 \mathrm{~h}$ before delivery which is in agreement with the findings of others (sheep: Challis, 1971; Robertson \& Smeaton, 1973; Tsang, 1978; Rawlings \& Ward, 1978a; goat: Challis \& Linzell, 1971; Rawlings \& Ward, 1978b; Thorburn et al., 1972). 
The data reported here show that during pregnancy the absolute values for progesterone, oestradiol and oestrone sulphate concentrations in peripheral plasma of the Barbary sheep studied fall between the values expected for sheep and goats, but that the pattern of change during pregnancy resembles that seen in the domestic sheep with respect to unconjugated oestrogens.

We thank Mr Tim Pearce for expert care and handling of the experimental animals, and Mrs J. A. Goode for technical assistance.

\section{References}

Bassett, J.M., Oxborrow, T.J., Smith, I.D. \& Thorburn, G.D. (1969) The concentration of progesterone in the peripheral plasma of the pregnant ewe. J. Endocr. 45, $449-457$.

Carnegie, J.A. \& Robertson, H.A. (1978) Conjugated and unconjugated estrogens in fetal and maternal fluids of the pregnant ewe: a possible role for estrone sulfate during early pregnancy. Biol. Reprod. 19, 202-211.

Casida, L.E. \& Warwick, E.J. (1945) The necessity of the corpus luteum for maintenance of pregnancy in the ewe. J. Anim. Sci. 4, 34-36.

Challis, J.R.G. (1971) Sharp increase in free circulating oestrogens immediately before parturition in sheep. Nature, Lond. 229, 208.

Challis, J.R.G. \& Linzell, J.L. (197I) The concentration of total unconjugated oestrogens in the plasma of pregnant goats. J. Reprod. Fert. 26, 401-404.

Denamur, R. \& Martinet, J. (1955) Effets de l'ovariectomie chez la brebis pendant la gestation. C. r. Séanc. Soc. Biol. 149, 2105-2107.

Drummond-Robinson, G. \& Asdell, S.A. (1926) The relation between the corpus luteum and the mammary gland. J. Physiol., Lond. 61, 608-614.

Flint, A.P.F., Burton, R.D. \& Heap, R.B. (1983) Sources of progesterone during gestation in Barbary sheep (Ammotragus lervia). J. Endocr. 98, 283-288.

Heap, R.B. \& Hamon, M. (1979) Oestrone sulphate in milk as an indicator of a viable conceptus in cows. $\mathrm{Br}$. vet. J. 135, 355-363.

Heap, R.B., Flint, A.P.F., Hartmann, P.E., Gadsby, J.E., Staples, L.D., Ackland, N. \& Hamon, M. (1981) Oestrogen production in early pregnancy. J. Endocr. 89, $77 P-94 P$.

Heap, R.B., Hamon, M. \& Fleet, I.R. (1984) Transport of oestrone sulphate by the mammary gland in the goat. J. Endocr. 101, 221-230.

Linzell, J.L. \& Heap, R.B. (1968) A comparison of progesterone metabolism in the pregnant sheep and goat: sources of production and an estimation of uptake by some target organs. J. Endocr. 41, 433-438.
Rawlings, N.C. \& Ward, W.R. (1978a) Correlations of maternal and fetal endocrine events with uterine pressure changes around parturition in the ewe. $J$. Reprod. Fert. 54, $1-8$.

Rawlings, N.C. \& Ward, W.R. (1978b) Fetal and maternal endocrine changes associated with parturition in the goat. Theriogenology 9, 109-120.

Ricketts, A.P., Galil, A.K.A., Ackland, N., Heap, R.B. \& Flint, A.P.F. (1980) Activation by corticosteroids of steroid metabolising enzymes in ovine placenta explants in vitro. J. Endocr. 85, 457-469.

Robertson, H.A. \& Smeaton, T.C. (1973) The concentration of unconjugated oestrone, oestradiol-17a and oestradiol-17 $\beta$ in the maternal plasma of the pregnant ewe in relation to the initiation of parturition and lactation. J. Reprod. Fert. 35, 461-468.

Sheldrick, E.L., Mitchell, M.D. \& Flint, A.P.F. (1980a) Delayed luteal regression in ewes immunized against oxytocin. J. Reprod. Fert. 59, 37-42.

Sheldrick, E.L., Ricketts, A.P. \& Flint, A.P.F. (1980b) Placental production of progesterone in ovariectomized goats treated with a synthetic progestagen to maintain pregnancy. J. Reprod. Fert. 60, 339-348.

Stabenfeldt, G.H., Drost, M. \& Franti, C.E. (1972) Peripheral plasma progesterone levels in the ewe during pregnancy and parturition. Endocrinology 90 , 144-150.

Thorburn, G.D. \& Schneider, W. (1972) The progesterone concentration in the plasma of the goat during the oestrous cycle and pregnancy. J. Endocr. 52, 23-36.

Thorburn, G.D., Nicol, D.H., Bassett, J.M., Shutt, D.A. \& Cox, R.I. (1972) Parturition in the goat and sheep: changes in corticosteroids, progesterone, oestrogens and prostaglandins F. J. Reprod. Fert., Suppl. 16, $61-84$.

Tsang, C.P.W. (1978) Plasma levels of estrone sulfate, free estrogens and progesterone in the pregnant ewe throughout gestation. Theriogenology 10, 97-110.

Received 21 December 1989 